\title{
The estimated impact of the COVID-19 epidemic in the general population of France
}

\author{
Laurent TOUBIANA ${ }^{\mathrm{a}}$ Jacques BOUAUD ${ }^{\mathrm{b}, \mathrm{a}}$ \\ anserm, Sorbonne Université, Université Sorbonne Paris Nord, UMR S_1142, LIMICS, \\ Paris, France, \\ ${ }^{\mathrm{b}}$ AP-HP, DRCI, Paris, France
}

All authors contributed equally to the work

"The authors have withdrawn their manuscript whilst they perform additional experiments to test some of their conclusions further. Therefore, the authors do not wish this work to be cited as reference for the project. If you have any questions, please contact the corresponding author." 